\title{
HOMAGE TO PROFESSOR OSCAR SAAVEDRA SAN MARTIN
}

\author{
E.H. SHIBUYA ${ }^{1, *}$ \\ ${ }^{1}$ Instituto de Física Gleb Wataghin, Universidade Estadual de Campinas, 13083-970 Campinas, SP, Brazil.
}

\begin{abstract}
.
Professor Oscar Saavedra San Martin passed away on 8 April 2018 at Bonvicino-Italy. The Organizing Committee of the $20^{\text {th }}$ International Symposium on Very High Energy Cosmic Rays-ISVHECRI-2018, held in Nagoya, Japan decided to pay a tribute to Oscar, born on 29 June, 1940 at LaPaz, Bolivia. During the banquet, a small presentation in honour to Oscar was scheduled in a special section of Wednesday 23 May 2018. His last participation was at the $19^{\text {th }}$ ISVHECRI held in Moscow, Russian Federation, during the period 22-27 August 2016. Oscar joined the BASJE-Bolivian Air Shower Joint Experiment in 1966, a collaboration between Bolivia and Japan. The aim of BASJE was to search for high energy $\gamma$ 's coming mainly from the center of Galaxy, due to the Chacaltaya location. From 1967 to 1968 he served as Director of the Cosmic Ray Laboratory at Chacaltaya following the BASJE experiments. Due to his huge contribution to Bolivian Science, Oscar received in 2009 the Doctor Honoris Causa title and was nominated Scientific Ambassador of his motherland. He gained his Doctorate from Milan University in 1964 and after immigration to Italy was a staff member of Torino University. On his retirement Torino University awarded him the title of Emeritus Professor.
\end{abstract}

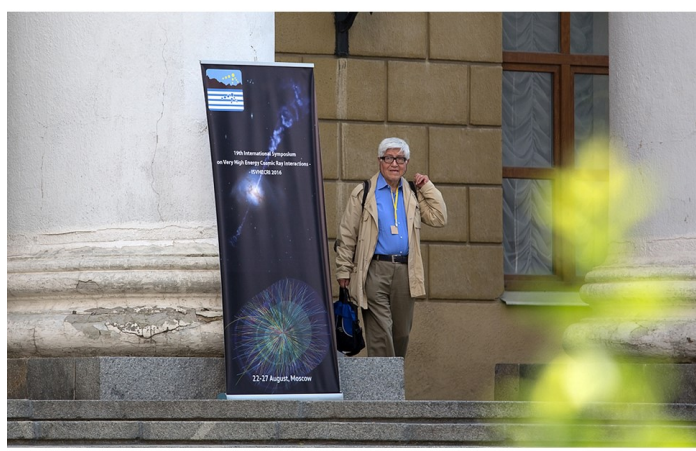

Figure 1. Last participation at the $19^{\text {th }}$ ISVECRI-2016, Moscow.

\section{Oscar and ISVHECRI}

Oscar was a frequent attendee of a series of biennial workshops/symposia held in even years, between the ICRC/IUPAP conference years. His first contribution was found in 'New Proposal of Cosmic Ray Experiment at Mt. Chacaltaya-Experiment OMEGA' as co-author at the $6^{\text {th }}$ ISVHECRI-1990, 8-17 July in Tarbes, France. He served as chairman of the $10^{\text {th }}$ ISVHECRI, 12-17 July 1998, at the Laboratori Nazionali del Gran Sasso, Assergi, Italy and after 2006 succeeded the late Prof. Sergei A. Slavatinsky as chairman of the Emulsion Chamber Committee. Fig 1 shows him at his last participation in Moscow, 2016.

*e-mail: ehiros@hotmail.com

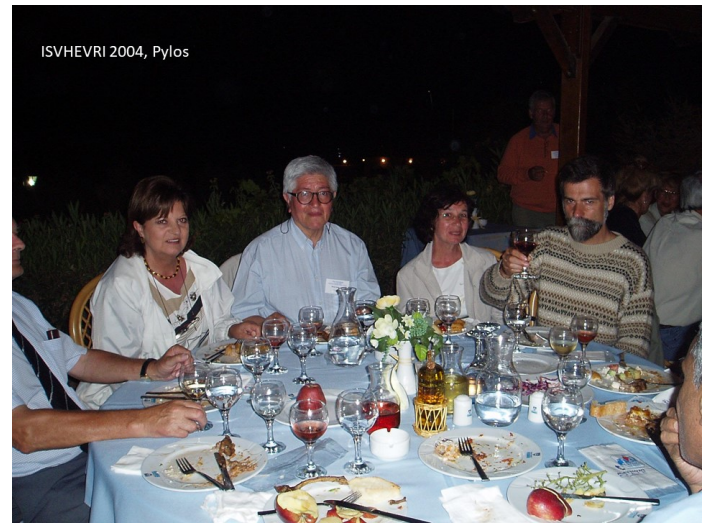

Figure 2. $13^{\text {th }}$ ISVHECRI-2004, Pylos.

Oscar's participation at the $13^{\text {th }}$ and $16^{\text {th }}$ ISVHECRI's are shown in Figs 2 and 3, respectively.

Oscar's first participation was only at the $6^{\text {th }}$ ISVHECRI-1990, because the 5 previous symposia were concerned with Hadronic Interactions results obtained from Emulsion Chamber and Accelerator experiments. It coincided with the inclusion of EAS experiments as a new topic to the previous ones, as the historical material presented in the Appendix shows.

The construction of Higher Energy Accelerators, mainly Cern/ISR, Tevatron, Cern/SPS, induced Cosmic Ray Experimental Groups to improve their detectors and so, to reach a consensus, Hybrid Experiments would be proposed, using Emulsion Chambers, plastic scintilators or using Cerenkov radiation detectable in fluids like Air 


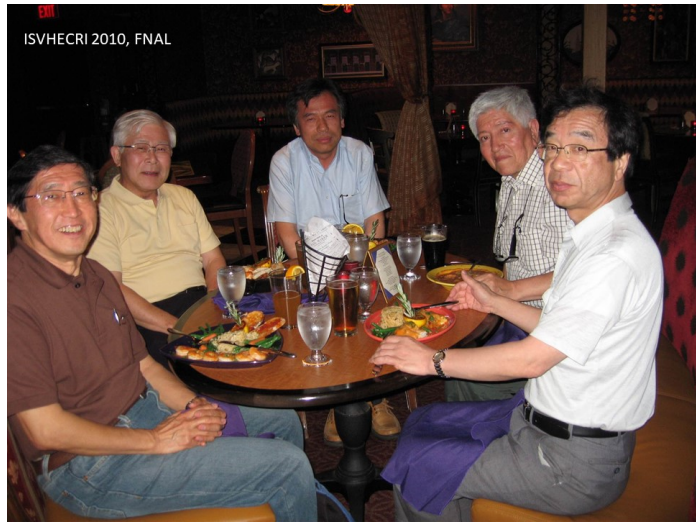

Figure 3. $16^{\text {th }}$ ISVHECRI-2010, Batavia.

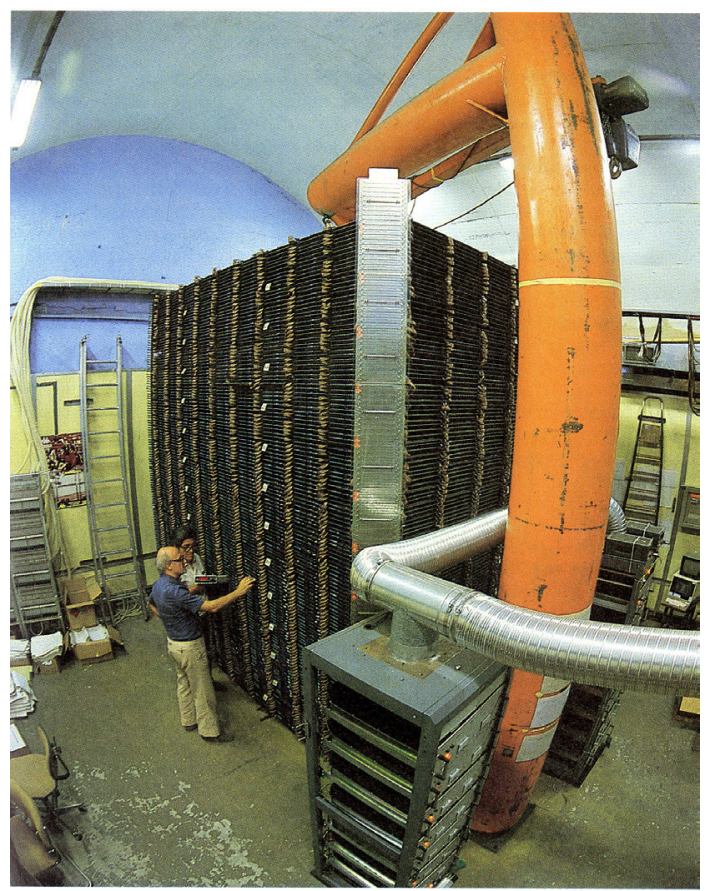

Figure 4. Nusex experiment.

and Water. EAS experiments concentrated on Morphological Studies and intended to get clues for the Origin of Cosmic Rays. When the Auger Project was proposed, we were told that Prof. Masatoshi Koshiba's statement was about the lack of Interaction Studies, in spite of the search of the GZK effect, the main object of the Auger Project.

In 1983 the Kamioka Underground Observatory was established with the KAMIOKANDE-Kamioka Nucleon Decay Experiment. Fig.4 is of the NUSEX-Nuclear Stability Experiment, where Profs. Bologna and Saavedra are seen in front of the proton decay detector. This photograph was taken from the book 'The Particle Explosion' by F. Close, M. Marten and C. Sutton. Both experiments, KAMIOKANDE and NUSEX observed a neutrino bundle from Supernova SN1987A using different techniques; KAMIOKANDE used a Cerenkov radiation detector in water whereas NUSEX used the electronic pulses produced inside streamer tubes. Another remarkable partic-

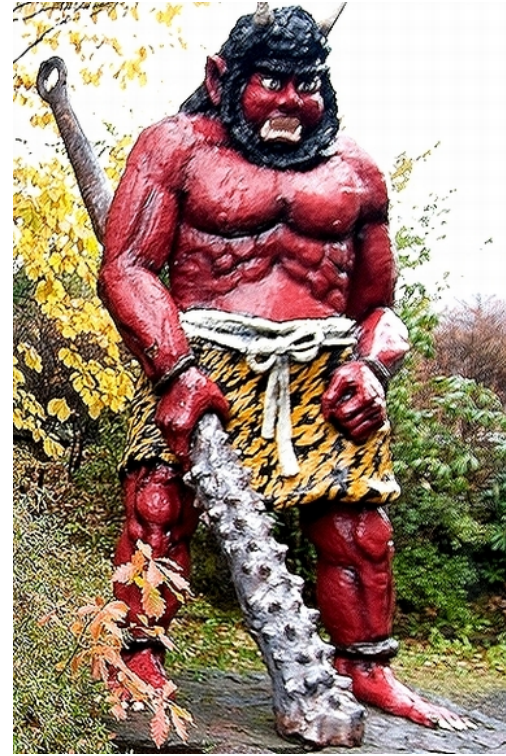

Figure 5. Japanese folklore representation of a demon.

ipation of Oscar was in the LVD-Large Volume Detector experiment.

\section{Similarities}

Luigi Luca Cavalli-Sforza, an eminent Italian geneticist wrote a remarkable book, 'Geni, popoli e lingue', the English version has the title 'Genes, peoples and languages'. As this homage to Oscar was given in Japan, it is maybe interesting to call attention about similarities between Japanese and Bolivians, like Oscar. We think that Japanese scientists of the BASJE-Bolivian Air Shower Joint Experiment, Brazil-Japan Collaboration, SYS-Saitama, Yamanashi, San Andres Collaboration and nowadays ALPACA-Andes Large area PArticle Project would feel a similarity with Bolivian Indians, at least with their eyes format. The purpose of this section is to show those similarities between Japanese and Primitive Peoples like Bolivians and Brazilians and we divide it into 3 subsections, inspired by the famous book of L.L. CavalliSforza.

\subsection{Genes}

Possibly, Amerindian Peoples and Japanese may have some similar genes that cause: a) Black Hair, b) Eyes format and c) Mongolian blue spots on the buttocks

\subsection{Peoples}

Both peoples, Bolivian and Japanese, have a similar folklore representation of a demon. Fig. 5 shows the folkloric Japanese demon. Photos taken at a Bolivian city, Santa Cruz de la Sierra shows the 'Diablada' (Demon's Festival). Figures 6 and 7 show a typical Bolivian folkloric festival where the similarities of Japanese and Bolivian demons can be seen. 


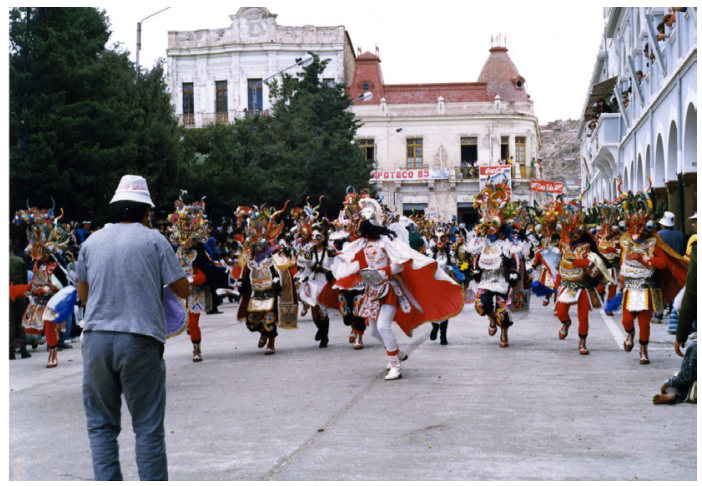

Figure 6. Demon's festival-I in Bolivia.

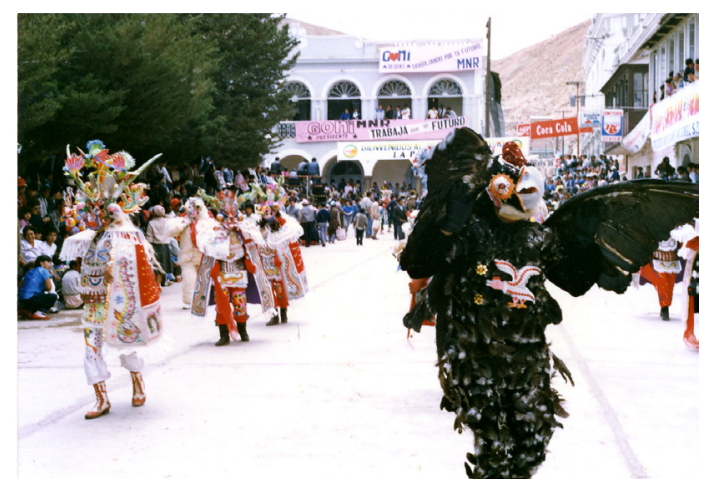

Figure 7. Demon's festival-II in Bolivia.

Another coincident behaviour of both peoples, Bolivian and Japanese, must be reported. They have the same habit of paying homage to persons who have passed away with a ceremony of a similar kind of party, Ukiyo in Japanese.

Fig. 8 shows the cover of a book written by a Brazilian Geologist and Archæologist, Luis Caldas Tibiriça. The title of the book written in Portuguese could be freely translated as: Comparative Studies of Japanese Language with Amerindian Languages-Evidence of pre-Colombian contacts. This cover shows similar images of Brazilian Indians sport (Huca-huca) with the traditional Japanese sport, Sumo.

\subsection{Languages}

According to Luis Caldas Tibiriça, author of the book mentioned earlier, there are around 1,000 similar words between the Japanese Language and a Tupi Language, one of a Brazilian Primitive People's Language. Both are phonetically in origin and so, not only the pronunciation of words but also the meaning are similar. A small sample is shown in the Table.

\section{Comments}

Professor Oscar Saavedra San Martin promoted various lectures and meetings at LaPaz, the political capital of Bolivia. Most

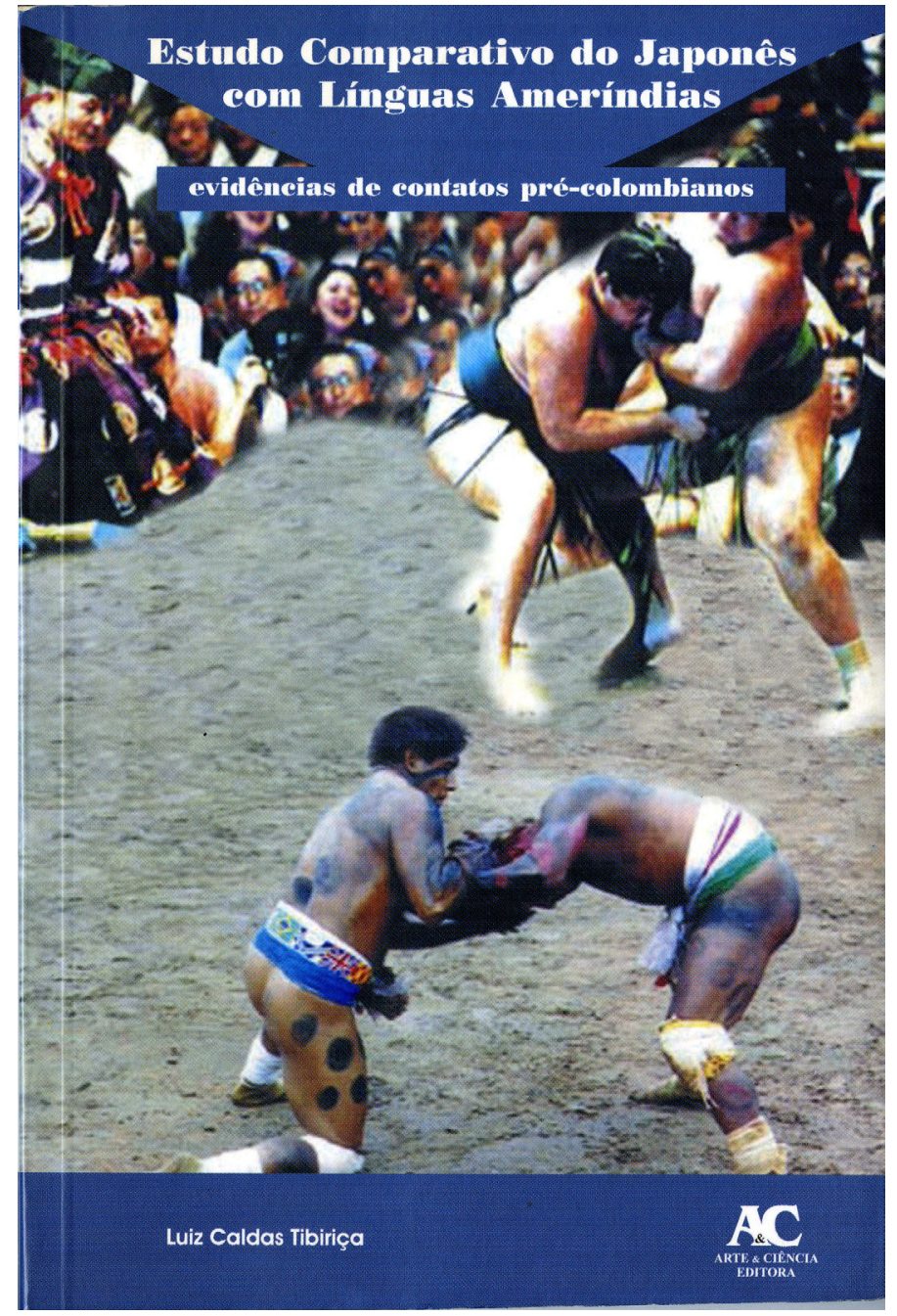

Figure 8. Huca-huca and Sumo wrestlers.

contribution are on Cosmic Rays, but also on general Physics, such as 'The legacy of Galvani and Volta to the contemporary Science'. His contribution to Astroparticle Physics started from the beginning of his scientific career in 1966, when he joined the BASJE experiment at the Chacaltaya Cosmic Ray Laboratory. This is a privileged site due to its high altitude and location at the Geomagnetic Equator and so ideal to search for high energy gamma rays. Oscar would be proud of the ALPACA-Andes Large area PArticle Project running in his motherland and looking for higher energy $\gamma$ 's.

Oscar promoted various collaborations, between Bolivia and Italy, Italy and ex-USSR, Italy and Brazil. Brazilians owe much to Oscar, his strong support provided a fruitful co-operation between both countries, Brazil and Italy.

We miss you Professor OSCAR SAAVEDRA SAN MARTIN, rest in peace.

\section{Acknowledgments}

EHS is grateful to the Organizing Committee of the $20^{\text {th }}$ ISVHECRI-2018 for the kind invitation to present this hommage to Oscar. Special thanks also to Professors Akinori Ohsawa, Bryan Pattison and Masanobu Tamada for their help during and after the Nagoya Symposium in the preparation of this contribution. 


\begin{tabular}{|c|c|c|}
\hline English & Japanese & Amerindian \\
\hline Cranium & Togai & Tugai \\
\hline Neck & Kubi & Kupi, Kubi \\
\hline Nose & Hana & Aná \\
\hline River & Kawa & Kaua, Kawa \\
\hline Mountain & Yama & Sa(j,y)ama (Bolivia Mountain), Yama-chice (Canada Mountain) \\
\hline Night & Yoru & Assa \\
\hline Morning & Assa & Misu \\
\hline Water & Mizu & Mirã \\
\hline Future, Futurely & Mirai & \\
\hline
\end{tabular}

Table 1. Comparison of similar words

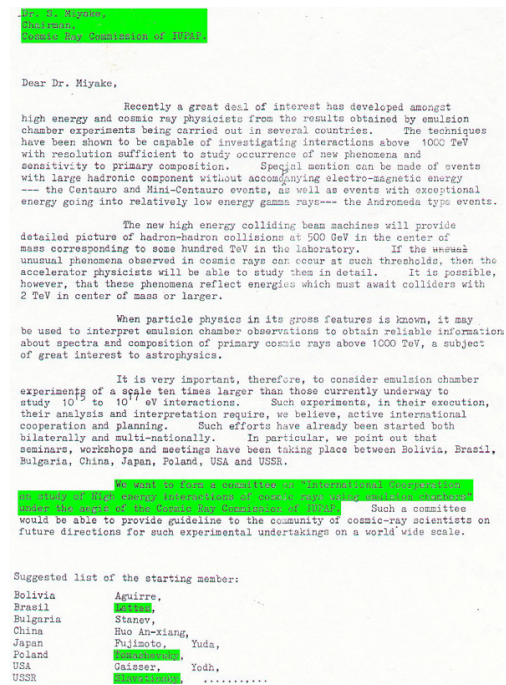

Figure 9. Request to C4/IUPAP1.

\section{Appendix}

On the occasion of the $20^{\text {th }}$ ISVHECRI we are taking this opportunity to pay homage to not only Oscar Saavedra but also to the pioneer participants of this series of symposia, pioneers such as Profs. Alexander Borisov, Katsuaki Kasahara and Masanobu Tamada, still active at this symposia and the late Profs. Cesare M.G. Lattes(1924-2005), Sergei A. Slavatinsky(1927-2006), Alojzy K. Tomaszewski(1925-2006). At Weihai, China the organizing committee of $14^{\text {th }}$ ISVHECRI, 15-22 August 2006, a homage to them took place. We also pay due homage to Prof. Akinori Ohsawa, who was asked by Prof. Yoichi Fujimoto, the main founder of these symposia, to continue it following his retirement.

On 29 October 1980 a letter was addressed to Professor Saburo Miyake, at that time Chairman of the Commission on Cosmic-rays C4, IUPAP-International Union of Pure and Applied Physics. It was developed during the First Soviet-Japanese Symposium on high energy Cosmic Rays and its main intention was a request to support a committee on 'International Cooperation of Emulsion Chamber Experiments'. The first letter, Fig.9, suggesting the names to form the committee and the second one, Fig.10, signed by Profs. S.Slavatinsky, T.Yuda and Y.Fujimoto who were present at Nakhodka, ex-USSR.

This First Soviet-Japanese Symposium on high energy Cosmic Rays was held during 20-29 October 1980 at Nakhodka, exUSSR and it is considered to be the $1^{\text {st }}$ ISVHECRI, although it

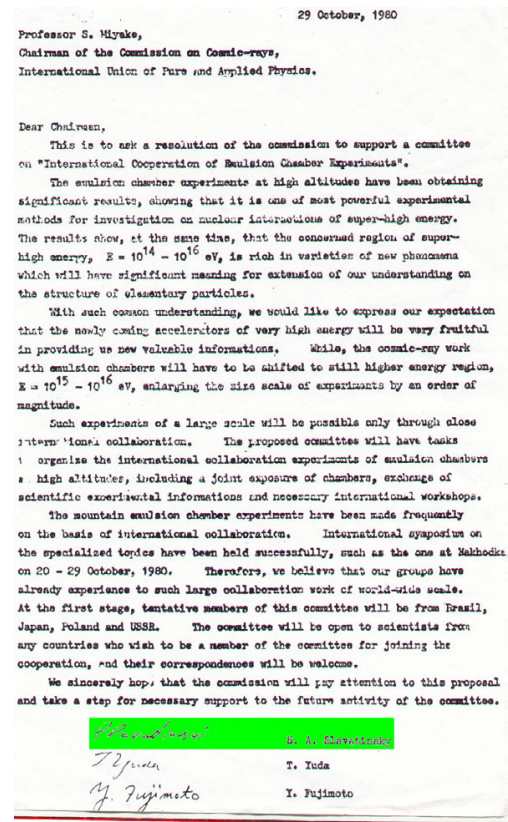

Figure 10. Request to C4/IUPAP2.

was only at the $5^{\text {th }}$ ISVHECRI/IUPAP that this name was consolidated. This simposium, under the chairmanship of Prof. Alojzy K. Tomaszewski, was held during 29Aug-06 September 1988 at Łodz, Poland.

Turning back to the Nakhodka symposium, chaired by Prof. Sergei A. Slavatinsky, historical photos are presented in Fig.11.

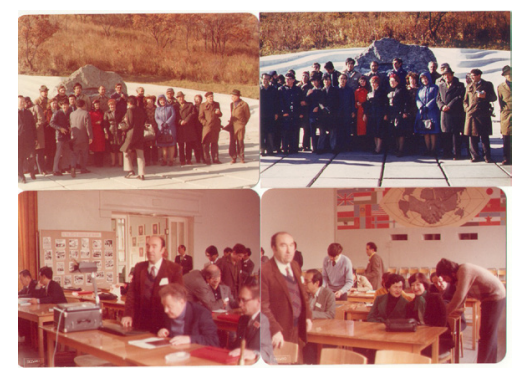

Figure 11. Nakhodka.

Following the Nakhodka meeting, Workshops on Cosmic Ray Interactions and High Energy Results were held in two countries, Bolivia, LaPaz City and in Brazil, Rio de 


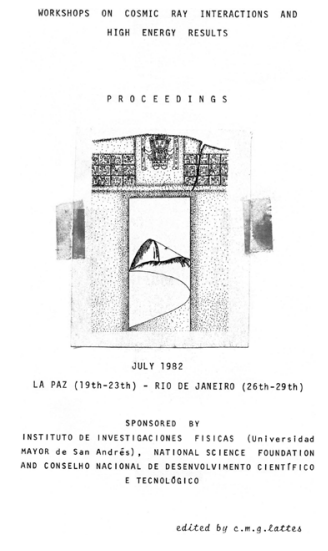

Figure 12. Cover of LaPaz and Rio de Janeiro proceedings.

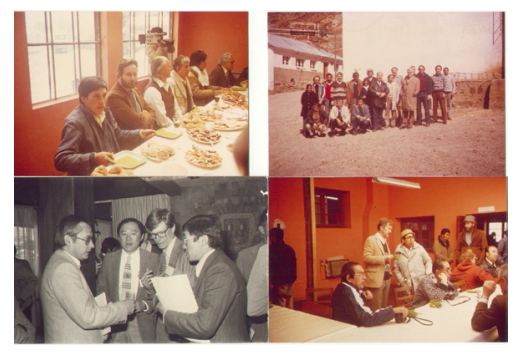

Figure 13. Worshop at LaPaz.

Janeiro City and some of the attendees visited Campinas City. For this and subsequent symposium an Emulsion Chamber Committee was constituted by Chairman:C.M.G.Lattes, ViceChairman:S.A.Slavatinsky and Secretary:Y.Fujimoto.

After the Nakhodka meeting the Commission on Cosmicrays $\mathrm{C} 4$, of the International Union of Pure and Applied PhysicsIUPAP authorized, at the $17^{\text {th }}$ ICRC Conference held in Paris 1981, these even years symposia to be held under the aegis of IUPAP. As the Nakhodka Symposium was dedicated to Cosmic Rays, it was considered necessary to include High Energy results obtained at particle accelerators, therefore the name of Bolivia-Brasil meetings. At these meetings one presenter was Prof. David Cline from CERN and another one was Prof. Leon Voyvodic from FNAL, both from the biggest delegation (10 scientists) of USA. Before the Rio de Janeiro meeting (26-29 July 1982) Prof. Shunichi Hasegawa was at CERN and there, Prof. Carlo Rubbia complained about the overlapping period with the $21^{s t}$ ICHEP:Paris, France (26-31 July, 1982). There, was presented the contribution 'Results from the UA1 Experiment at the CERN SPS Collider'. These results were from the proposal (approved on $29^{\text {th }}$ June 1978) of UA1, 'A $4 \pi$ SOLID ANGLE DETECTOR FOR THE SPS USED AS PROTONANTIPROTON COLLIDER AT A CENTRE OF MASS EN-
ERGY OF $540 \mathrm{GeV}$ '. In there we can read 'In this new energy domain even "conventional" hadron physics takes on a renewed interest, especially in view of the possible change of régime suggested by cosmic-ray experiments'. The comparison (Events of Very High Energy Density) was published by G.Pancheri and C.Rubbia in Nucl.Phys.A418(1984),117c, and although B-J Collaboration had observed the increase of mean transverse momenta with multiplicity and energy of secondaries since the time of the publication CHACALTAYA Emulsion Chamber Experiment and Related Papers, Prog.Theo.Phys.Supp.47(1971), nowadays these observations are known as Feynman scaling breaking. In fact this breaking was observed in 1974 in Armando Turtelli Jr.'s doctor thesis; 'Multiple Production of Pions at Cosmic Radiations Energies and Comparison with I.S.R./CERN data'.

Fig.12 shows the logo, composed of the Puerta del Sol at Tihuanako village and the Sugar Loaf in Rio de Janeiro. By the way this logo was created by Prof. Armando Turtelli Jr. depicting from two individual photos.

Some photos of these workshops are shown in Figures 13 and 14.

The fist four meetings have different names as listed below.

I - First Soviet-Japanese Symposium on Cosmic Rays, 20-29 October 1980, Nakhodka, ex-USSR.

II - Worshops on Cosmic Ray Interactions and High Energy Results, 19-23 July 1982, LaPaz-Bolivia and 26-29 July 1982, Rio de Janeiro-Brazil.

III - International Symposium on Cosmic Rays and Particle Physics, 19-23 March 1984, Tokyo, Japan.

IV - International Symposium on Cosmic Ray Superhigh Energy Interactions, 29 October - 03 November, 1986, Beijing, China.

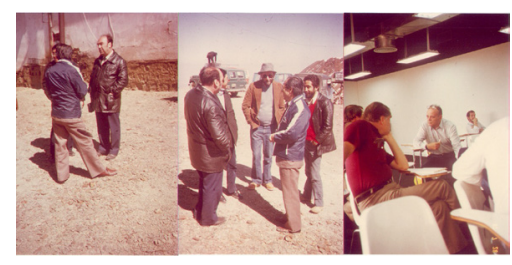

Figure 14. Workshops at LaPaz and Rio de Janeiro. 